\title{
Alan F. Weissman: Top score for the Radiology Boards Q\&A for the Core and Certifying Exams
}

\section{Thieme, New York Stuttgart Delhi Rio de Janeiro, 2018, 735 p., format $21.5 \times 28 \mathrm{~cm} \times 3.5 \mathrm{~cm}$, 924 illustrations, ISBN 978-1-62623-409-3, eISBN 978-1-62623-410-9}

\section{Bruno Grignon ${ }^{1}$}

Received: 16 March 2018 / Accepted: 19 March 2018 / Published online: 26 March 2018

(c) Springer-Verlag France SAS, part of Springer Nature 2018

In keeping with the title, this book aims at providing the ideal preparation resource for the American Board of Radiology and its equivalents.

It is composed of 17 sections. The first 14 sections are subsequently devoted to breast, cardiac, diagnostic radiology, gastro-intestinal, genitourinary, interventional, musculoskeletal, neuroradiology, nuclear medicine, pediatric, thoracic, ultrasound/reproductive/endocrinology, vascular, and general radiology imaging. Two other sections treat of physic safety and artifacts in imaging. The last section, available online, deals with noninterpretative skills.

Each section includes four types of test cases of varying complexity, respectively entitled: essentials, details, image rich, and more challenging. Each test case is presented in the same format, on a two-page spread. "Essentials" begins with a case presentation including high-quality images and boardtype multiple-choice on one page, followed by answers and explanations on the second page, including a short list of suggested readings, and key top tips at the bottom of the page. The presentation is the same for "Details", including ten "rapid-fire" questions. "More challenging cases" follows also the same format as "Essentials", with cases of higher degree of difficulty. "Image rich" presents multiple images of specific diagnoses, which must be identified.

The editor is a practicing diagnostic radiologist, in Las Vegas, Nevada, USA. A panel of 31 American contributors, experienced practicing radiologists and expert question writers, has collaborated in writing this work.

Aiming at providing both rapid and lasting mastery of major topics in radiology, this book is chiefly designed to help radiology residents prepare for Radiology Boards or other similar radiology examinations, and improve their test scores. More generally, it offers a practical, complete, and easy-to-use pedagogical tool. Education being a lifelong process, it may also be helpful for practicing physicians.
Bruno Grignon

b.grignon@chu-nancy.fr

1 University of Lorraine, CHU Nancy, Nancy, France 